In press, Disability \& Society [author version accepted $19^{\text {th }}$ April 2016]

\title{
Vulnerability in custody: perceptions and practices of police officers and criminal justice professionals in meeting the communication needs of offenders with learning disabilities and learning difficulties
}

Sarah Parsons $^{*_{1}}$ \& Gina Sherwood ${ }^{2}$

${ }^{1}$ Southampton Education School, University of Southampton, UK

${ }^{2}$ School of Education and Continuing Studies, University of Portsmouth, UK

* For correspondence:

Southampton Education School, Highfield, University of Southampton, SO17 1BJ, UK

Email: $\underline{\text { s.j.parsons@soton.ac.uk }}$

Telephone: 02380592977

\section{Funding}

This work was supported by Autism Hampshire, Hampshire Constabulary, and The Appropriate Adult Service. The research was independently conducted and reported by the authors at the University of Southampton. There are no conflicts of interest.

\section{Acknowledgements}

We are very grateful to our funding partner organisations for facilitating access to custody centres and potential participants. The partner organisations agreed the general focus of the pilot project and also supported initial access to research sites and participants. The conduct of the research, including choice of interviewees, lines of questioning and the analysis and interpretation of the data were decided and managed independently by the authors. We thank all of our participants for their generosity with time and willingness to participate in the research. 


\section{Points of interest}

- People entering the Criminal Justice System (CJS) who are young and / or have a learning disability or difficulty are often found to experience problems in understanding their rights and entitlements.

- Those who work within the CJS have a responsibility for communicating clearly to anyone who is considered vulnerable to ensure they understand their rights in custody.

- This project piloted the use of a more accessible format of the rights and entitlements notice, using Widgit symbols, and asked professionals within the CJS about their experiences of using the accessible notice within custody.

- Their comments revealed where and how communication difficulties occur in custody, highlighting that how people communicate can become very fixed and difficult to change.

- The Widgit symbol rights and entitlements notice was viewed positively as a communication tool that could begin to change existing ways of providing information about rights and entitlements. 


\section{Abstract}

Information provision and communication within the Criminal Justice System (CJS) can be highly problematic for young people and adults with learning disabilities and difficulties. Paper-based communication is common, and mandated for the provision of rights and entitlements in custody, but such communication can be poorly understood, potentially leading to miscarriages of justice. This article uses the piloting of a more accessible version of the rights and entitlements notice in custody to explore the communication practices with vulnerable detained persons from the perspectives of professionals within the CJS. As a legally mandated text in a context heavily imbued with organisational power, the rights and entitlements notice in custody has sociological significance as a lens through which organisational practices, and understandings, can be examined. The stressful, fast-paced and transitional context of custody shapes communication and interaction in ways that are challenging for the detained person and also the professionals who support them.

Keywords: learning disabilities, custody, rights and entitlements, accessibility, communication, texts 


\section{Introduction}

Questions have been asked about the extent to which the Criminal Justice System (CJS) '....takes adequate account of the structural, institutional barriers for disabled people' (Diesfeld et al., 2008). One of the major structural barriers for disabled people in the UK is the provision of written information in non-accessible forms (Talbot, 2010). This paper is situated in the context of a project that piloted and evaluated the use of an accessible 'rights and entitlements' notice designed for young people and vulnerable adults ${ }^{\mathrm{i}}$ in police custody (Parsons \& Sherwood, 2015). The notice incorporated Widgit Symbols and was trialled in two custody centres with positive indications for future use (Parsons \& Sherwood, in press). We focus on the views of custody personnel and other CJS professionals about the challenges and practices of supporting the communication needs of vulnerable people in custody, including those with learning disabilities and difficultiesii, as a way of illustrating how at least some structural barriers might be ameliorated through the use of accessible information.

\section{The Rights and Entitlements notice}

One of the most critical aspects of information provision within the CJS in the UK is at the point when someone is taken into custody. Under the statutory obligations of the Police and Criminal Evidence Act (PACE) 1984 Section C, custody officers must ensure that a person is giving a written notice that sets out their three main continuing rights in custody [the right to have someone informed of their arrest; the right to consult privately with a solicitor and that free independent legal advice is available; and the right to consult the full Codes of Practice], as well as the arrangements for obtaining legal advice; their right to a copy of the custody record; and the police caution. A detained person must be informed in writing about their entitlements while in custody including the provision of food and drink, medical attention, reasonable standards for physical comfort, circumstances when an appropriate adult can assist, the conduct of interviews, and how to make a complaint. Additionally, under PACE Code C, paragraph 11.15, if the detained person is considered by the custody officer to be 'mentally disordered or otherwise mentally vulnerable' then the custody officer has a duty 
to require an appropriate adult attends the police interview in order to support the understanding of the detained person during the process.

The written rights and entitlements notice is now available in 54 different languages as well as in 'easy read' format, containing simple words and pictures (although is 33 pages long; Home Office, 2014). The standard English version of the rights and entitlements notice comes as a z-fold leaflet and is shown in Figure 1; it is a densely worded document in small font and is given to everyone entering custody [Figure 2 shows the Widgit Symbol version for comparison].

${ }^{* * *}$ Insert Figures $1 \& 2$ about here ${ }^{* * *}$

However, perhaps because of the significance of the rights and entitlements notice in making the detainee aware of their rights, this notice has also been highlighted as causing '...particular difficulties in comprehension for people who have learning disabilities' (Gendle \& Woodhams, 2005; p.71). These difficulties have been known for a long time and include concerns that people may not understand the caution or the rights in the notice due to poor comprehension and literacy (Murphy \& Clare, 1998), and may not tell custody officers that they cannot understand the information for fear of the stigma and discrimination attached to revealing a learning disability or difficulty (Talbot \& Jones, 2010; Keilty \& Connelly, 2010). Therefore, even though someone may have rights in this context, whether or not they are willing or able to exercise them raises fundamental questions regarding the equality of treatment for people with disabilities in the eyes of the law. Specifically, Article 5 of the $U N$ Convention on Rights of Persons with Disabilities (UNCRPD; 2006), establishes the rights of people with disabilities to 'equal protection and equal benefit of the law' and states that:

In order to promote equality and eliminate discrimination, States Parties shall take all appropriate steps to ensure that reasonable accommodation is provided.

However, many challenges in meeting these commitments within the CJS in the UK have been identified. For example, the Prison Reform Trust's No One Knows research programme 
(Jacobson, 2008) highlighted particular challenges relating to the inconsistent treatment of offenders with learning disabilities and mental health difficulties due to acknowledged difficulties from front-line police officers in identifying their needs and responding appropriately (also Bailey, Barr \& Bunting, 2001; Cant \& Standen, 2007; Gendle \& Woodhams, 2005; Henshaw \& Thomas, 2012; Keilty \& Connelly, 2010). This is in a context where it is estimated that $20-30 \%$ of all offenders in the UK '...have learning difficulties or learning disabilities that interfere with their ability to cope within the criminal justice system; of this group 7\% will have very low IQs of less than 70' (Jacobson, 2008; p. iii), although the actual numbers could be higher than this (Williams, Swift \& Mason, 2015). Additionally, for any offender who may have difficulties with reading and / or writing, navigating and understanding the systems of the CJS can be a significant challenge because 'Prisons are largely paper-based regimes' (Talbot, 2010; p.36). Indeed, Talbot (2010) interviewed 154 prisoners with learning difficulties or disabilities and found that over twothirds had experienced difficulties with reading and completing written forms and information within the CJS.

The implications of this challenge are substantial; if someone finds it difficult to understand crucial information regarding their rights, entitlements, and processes within the CJS, '...there is a significant risk of disadvantage and the potential for miscarriage of justice' (Jones \& Talbot, 2010; p.3; also Hellenbach, 2012). Mitigating such risks also has important implications for the professionals within the CJS who are responsible for ensuring that essential information is clearly communicated. Consequently, it is vital to explore the perspectives of the professionals with these responsibilities in order to understand how communication needs in custody may be more effectively managed and met.

\section{The importance of making information more accessible in the CJS}

Given the serious implications of not understanding the formal processes within the CJS, reports have highlighted the need for changes to be made to the way in which information is conveyed in order to support more effective communication and understanding between a 
detained person and the professionals within the CJS (Henshaw \& Thomas, 2012). For example, Jacobson (2008) recommended that one of the ways in which policy and practices for supporting offenders with learning difficulties and disabilities can be improved is through '...providing more accessible written information and forms' (p.36). Similarly, Swift, Johnson, Mason, Shiyyab and Porter (2013) found that one of the biggest gaps identified by CJS professionals in meeting the needs of people with learning disabilities seeking advice about the law was in having access to appropriate communication tools that can support understanding. Consequently, they recommended the need to develop information in easier to read formats as part of their good practice guidance.

Although there have been some improvements to the accessibility of information within the CJS since the publication, and recommendations, of Jacobson' (2008) No One Knows report (Talbot, 2010; Poynter, 2011), we could not find any published information regarding formal evaluations of these materials being used in practice. A recent report by Her Majesty's Inspectorate of Probation (2014), focusing on the period from arrest, through custody and sentencing, concluded that despite the recommendations of the Bradley report (2009), and subsequent investment by the Coalition government in liaison and diversion services at police stations and courts (PRT, 2013), ‘...the needs of offenders with learning disabilities are often overlooked... examples of good practice were the exception rather than the norm' (p.4). This suggests that there are still considerable efforts that need to be made in order to equip police officers with appropriate tools and understanding to enable them to identify and support people with learning difficulties and disabilities more effectively within the CJS. We contend that this area deserves more scrutiny in terms of recognising where the challenges lie not only for the detained person but also for the professionals who interact with, and support, them.

\section{Empowerment and access}

This raises questions about the extent to which someone may or may not be empowered by the provision of written information in a more accessible form. Gudjonsson, Clare and Cross 
(1992) trialled a revised version of the rights and entitlements notice (formerly the 'Notice to Detained Persons') with simpler language and shorter sentences and found that the comprehension by people with learning disabilities of their rights was improved. However, as Rock (2006) notes, this study was carried out in an experimental lab-based setting with participants who were not in custody and not, therefore, experiencing any of the distress, anxiety or disempowerment likely to accompany such an experience. Consequently, whether such a revised format would be useful for supporting understanding in custody remains an open question; the revised version was never adopted for use by the Home Office.

Moreover, access to information for people with learning disabilities and difficulties - and the extent to which individuals may feel empowered through gaining access to information also extends far beyond the simple provision of information in more accessible formats (Young \& Quibell, 2007), not least because custody is an inherently disempowering context for any detained person. Nind and Seale (2009) discuss the concept of 'access' more widely and remind us that access (to information, society, services, relationships) is complex, multidimensional and bi-directional. In other words, that access requires an interaction between a person with a learning disability or learning difficulty and others, who come with their own understandings and ideas about what people with learning disabilities or difficulties can or cannot do (cf. Dowse, 2009).

Extending this idea further, Williams et al., (2015; p.707) argue that actual and perceived competence is 'malleable' because it depends on interactions between an individual and their environment; any of us can become more, or less, disabled in any context depending on the levels of social inclusion and support provided (also Goodley, 2011). This idea is especially relevant to the context of custody where there is a lack of awareness and understanding by frontline officers about the capabilities and intentions of individuals with learning disabilities or difficulties (e.g. Bradley, 2009; Bailey et al., 2001), not least because such individuals can be very difficult to identify unless they self-disclose (Cant \& Standen, 2007; Jacobson, 2008). Moreover, individuals may not even know themselves that they have a 
difficulty until they are faced with such a challenging context (Williams et al., 2015). Thus, how information is provided to anyone entering custody, alongside the attitudes and awareness of those who are in positions to provide input and support, are vitally important considerations.

\section{The significance of the Rights and Entitlements notice as a written text}

The main point of interest here is the way in which providing the rights and entitlements notice in a more accessible format offers a lens on organisational understandings and practices relating to the communication needs of people with learning disabilities and difficulties within the CJS. This draws upon Smith's (2001) conceptualisation of texts as material entities that shape and co-ordinate people's activities within particular settings, such that the texts are also able to inform us about how actions within those settings reproduce or reflect messages and practices of the wider institution or organisation. Smith (2001) argues that:

Texts and documents make possible the appearance of the same set of words, numbers or images in multiple local sites... The text itself, as a material presence (paper, electronic and so on) is produced, read (watched, listened to) in particular local settings by particular people. People's activities in local settings are in this way connected into social relations organized by the text... When a text is read, watched or heard it brings consciousness into an active relationship with intentions originating beyond the local. Texts therefore are key devices in hooking people's activities in particular local settings and at particular times into the transcending organization of the ruling relations... (p.164).

Similarly, Walby (2005) argues that 'texts are not inert' (p. 192) and, instead, become active components of social relationships through their activation (use) by the social actors within any context. Thus, social relations, and the individual interpretations and subjectivities inherent in these, are both activated by and reflected in, the use of texts. 
The rights and entitlements notice has special status as a text within the early stages of a detained person's interaction with the CJS. Its existence and content, as well as the timing of how and where the text is deployed, are mandated by law. It is, therefore, heavily imbued with the power of the institution through which it is deployed and its use sets in motion exchanges and interactions between a detained person and others within the CJS. As Rock (2006) notes '...the delivery of rights is not a simple transaction of facts' (no page numbers), and so the rights and entitlements notice is not simply a neutral piece of paper. Any changes to the notice, therefore, are not trivial since those changes also potentially represent alterations to well-established social interactions, and understandings, within the particular context of a custody centre. Thus, while the development of a rights and entitlements notice in a more accessible form (whether that be symbol-based or a different format) might be viewed on one level as a straightforward reasonable adjustment aimed at supporting the comprehension of people with learning disabilities and difficulties in custody, the significance of such a development in practice may not be experienced or perceived as straightforward. The discussions with CJS professionals below reveal the challenges as well as potential for supporting communication practices of such a development.

\section{Methodology}

Rationale for the use of symbol-based information. More details about the overall design and approach of the Widgit Symbol custody sheet project can be found in Parsons and Sherwood (2015). Nevertheless, brief clarification of the context and rationale for implementing symbol-based information is important. The authors were independent evaluators of a pilot project initiated by Autism Hampshire and Hampshire Constabulary in response to a custody nurse who approached Autism Hampshire and asked if the organisation could support her work in developing a custody sheet to support her client base. She felt there were communication needs of people on the autism spectrum not being adequately met in custody, despite the existence of the Home Office Easy Read version of the 
rights and entitlements notice. Preferences for, and effectiveness of, different accessible formats vary and so symbols may not be the answer for everyone; this context is covered in more detail elsewhere (Parsons \& Sherwood, 2015).

The symbol materials were developed with the input of communication experts from Widgit and Autism Hampshire, who advised on the simplified text and symbol formats. These formats and the appropriateness of the information provided were checked, and approved, by Hampshire Constabulary's PACE advisor. In addition to the mandated rights and entitlements notice (Figure 2), more details about specific procedures and entitlements in custody were made available as A4 laminated sheets in a folder that could be used according to the custody officer's discretion (see Figure 3).

\section{***Insert Figure 3 about here ${ }^{* * *}$}

Although initially developed with the needs of people with autism in mind, it was felt that the symbol notice could be useful for anyone who may struggle with literacy and so during the pilot implementation of the sheets in custody centres officers were asked to give the sheets to '... anyone who you think may be vulnerable or have difficulties communicating and understanding'. The main point of this pilot evaluation was not to establish whether the symbol-based approach was better than other ways of making information more accessible. Rather, the focus was on exploring stakeholder perspectives on the acceptability and feasibility of using information in symbol-based form, in the custody context. Thus, the positioning of the text as a lens through which organisational practices can be scrutinised could have been applied here regardless of the specific format used to present the information in a more accessible way.

Sampling rationale. Given the focus on stakeholder views, and the small-scale nature of this pilot study, the project gained insights from people with, and without, direct experiences of the CJS (41 participants in total). This paper is interested specifically in the communication practices between CJS professionals and detained persons in custody and, therefore, focuses 
only on the views of the 29 participants with direct experience of this context. The views of other participants without direct experience of the CJS are reported elsewhere (Parsons \& Sherwood, 2015, in press). While it would have been preferable to also include the responses of those who had received the sheets in custody, this was not possible in the time-scale and available resources of the project which means that vital perspectives are not included (cf. Talbot, 2010; Williams et al., 2015).

Participants. Twenty-six people took part via individual interviews; this number comprised: fourteen custody personnel (including sergeants and inspectors); one family court barrister; two managers within the youth offending team; two defence solicitors; two people involved in the magistrate service; four Appropriate Adultsiii (AAs), and one legal representative. Three additional AAs took part in a small focus group discussion. The custody personnel interviewed had taken part in a 4-week pilot of using the Widgit Symbol rights and entitlements notice in custody on a discretionary basis and so had the opportunity to give them to detained persons (Parsons \& Sherwood, 2015; in press).

Recruitment. Participants were recruited to the study though direct contact in custody centres or via a second party who recommended them or facilitated contact. All interviewees were given information about the nature and purpose of the pilot project and assured that their contributions were voluntary and would be anonymised. They signed a consent form to participate in the project and to be audio recorded. Interviews mostly took place in the interviewees' work location, but some were conducted by telephone. The project received ethical review and approval from the Faculty of Social and Human Sciences Research Ethics Committee at the University of Southampton [ref \#11930]. Additional permissions were obtained from the Hampshire Criminal Justice Group and a meeting of nineteen representatives of the CJS at the Central Family Court in London.

Interviews. The topics for discussion included each participant's views on the challenges of communicating information to detained individuals within the CJS; the possible outcomes of not meeting the information needs of individuals with learning disabilities or difficulties; 
and ideas about how to meet these needs more effectively. Attitudes towards the Widgit Symbol rights and entitlements notice were also explored in terms of its drawbacks and advantages as well as how, and, for whom the sheets might best be used. Open questions were adopted and probes and prompts applied to explore issues in greater depth to enable a relatively informal 'conversational' dialogue (Axinn \& Pearce, 2006).

Analysis. An iterative structure was applied that began with audio material being listened to several times and summaries of the answer to each question documented. Recordings were then revisited and comments written verbatim. These were scrutinised using an inductive method, creating meaningful categories that contained evidence of possible meanings behind responses linked to the role of a professional and a detained person (Denscombe, 2010). Table 1 summarises the number of direct quotes used in the following sections and how these are taken from across the different participants. Inevitably, within wordage constraints, it is not feasible to include direct quotes from every participant.

\footnotetext{
${ }^{* * *}$ Insert Table 1 about here ${ }^{* * *}$
}

\section{Findings and Discussion}

\section{The ossification of existing 'ways of doing' within the CJS}

The discussions with CJS professionals underscored the challenges inherent within the system in effectively meeting the communication needs of vulnerable people in custody; most notable were the (implicitly) fixed expectations and understandings about current practices and how these impacted on the experiences of individuals. For example, interviewees acknowledged that the current ways of operating and communicating were often exclusionary and unhelpful, resulting in a lack of understanding by the detained person about their rights:

'...they may not have any concept of what you've actually been saying and then you look at them nodding your head saying "do you understand" and they say "yes"... it happens frequently.' Solicitor 2 
'...I think just the visual look or our rights sheet is quite formal, it can seem quite Draconian and people, I think, don't read our rights sheet...' Custody personnel 2

This lack of understanding about the system, and the notice, was discussed as having important implications for the detained person, in line with observations from Jones and Talbot (2010) and Hellenbach (2012), for example:

'it's more difficult for people with mental health conditions or children... I think it could be quite bad for them... because if they don't understand the full process then they may obviously do something that either maybe incriminates them which you have a right against doing... or they don't fully understand the seriousness of the situation or what they've actually been arrested for.' Legal Representative

However, there was also acknowledgement that this situation is also unhelpful for the professionals within the CJS, leading to questions about capabilities and professionalism:

'I am part of a criminal justice process and what you don't want, down the line is an example where ... a judge or a magistrate ... [says] actually we're going to throw the whole case out because ... clearly the suspect didn't understand their rights...because it's then very difficult to explain that to a victim...the judge says we haven't actually done things correctly and therefore the whole process is come tumbling down and you know that's not a nice situation for anyone to be in' Custody personnel 8

'...we're looking after the constabulary because if I make the wrong call at that point anything after that could be lost...' Custody personnel 11

Nevertheless, there was an unconscious sense of limited agency from many of the respondents; there was an acceptance of the status quo with regard to communication and information provision, however frustrating and inadequate this seemed: 
'...in custody we do this and then when it goes to court they do something different and for somebody with Asperger or autism they don't get it... it doesn't make sense...” Custody personnel 8

‘..juveniles... we can have them in as young as 11, 12... again when you sort of like explain that, it's quite a formatic [sic] way that we work and it's quite corporate...' Custody personnel 12

In other words, while there was broad awareness about the challenges of meeting information and communication needs in custody effectively, and sympathy towards this challenge, respondents regularly talked about procedures within the CJS as if they existed as practices separate from themselves. The mandated nature of the rights and entitlements text, and the subsequent interactions that follow from its deployment, initiate and shape the social relations between people in this specific contexts (Walby, 2005), including the actions of other social actors (AAs, solicitors, medical personnel).

As such, there are clear boundaries that are formed by the requirements of PACE and instantiated, in the very early stage of detention, by the provision of the rights and entitlements notice. While there is common agreement and discussion about the liminal status of detained persons at various stages of incarceration (e.g. Suttner, 2010; Ugelvik, 2013) there is less consideration of the roles of custody officers (cf. Arnold, 2008; Harvey, 2005; Jewkes, 2005; Young, 1986) within this liminal context i.e. they mediate an intermediate state or phase within the CJS and, as such, may have fleeting, transitional and intermittent contact with the detained person. The custody officers operate at the boundary of 'free and unfree' for the detained person (Suttner, 2010; p.7), and facilitate the contact of other professionals with them. As such, custody officers move in and out of the interaction with the detained person. In this context, it is perhaps not surprising that the custody personnel interviewed, as well as other professionals within the CJS, implied a lack of agency with respect to being able to influence or change communication practices with the detained person because such existing practices were perceived as the way things have to be done. 


\section{The ticking clock and the impact on communication}

Given that time spent in detention is governed by the law, it is not surprising that time featured strongly in many participants' discussions of the challenges in meeting the communication needs of vulnerable people in custody; something that Jacobson (2008) refers to as the 'custody clock' (p.37; see also Cant \& Standen, 2007). Generally, there were many areas identified as problematic with respect to time and how difficult it is to meet communication needs in the physical environment of custody:

'Usually with vulnerable adults you need a lot more time to go through things and there isn't that time and also the practical aspect of the surroundings, the cells, being with Perspex glass and not being able to sit down and sort of, next to them comfortably and sort of go through things with them it's just the physical environment in a prison... it's often quite difficult and time constraints...they are late to court so time is limited....you're often on the back foot in any event.' Family Barrister

The issue of time was also reflected in other, more specific, ways, for example, in relation to the automaticity of the booking-in process when someone arrives in custody and is first given notice of their rights. Both custody sergeants and other CJS personnel commented that this stage of communication can be perfunctory due to repetition and familiarity:

I realise that we can just be spiel, you know I've learnt the spiel and I just fly through it and for some people that haven't got the ability ...or who are struggling to understand because they are taken out of their safe zone or their way of doing things, it can be very difficult.' Custody personnel 11

There was acknowledgement and understanding that this interaction was unlikely to be helpful for the detained person: 
'They'll just go information overload, can't deal with this I'll just leave it, if I ignore it, it will go away. They pick them [the standard rights and entitlements notice] up and it's almost like you see the mist come over their eyes...' Custody personnel 7

However, it was also the perception from some CJS professionals that the detained person sometimes tended to yield or comply with procedures even when they did not understand them, in order to speed up the process so that they could be released, or moved on, more quickly:

'People will say anything if they know they are going to get out more quickly, it's surprising...that is another thing we worry about, do they say "yes I did it" for the sake of the fact that they need to get out.' AA 2

In this sense, the pressure of the ticking clock can collude with the desire of those in detention to get out as quickly as possible. There was certainly some distancing of the self from being able to do very much about this situation, as illustrated by this custody officer who discussed his views about the potential implications of using the Widgit Symbol rights and entitlements notice rather than the standard version:

'...that needs to have a lot more time to sit down with someone and go through it step by step using the sheets that you've got there ... who should do that I don't know, I don't think it sits with the custody sergeants...' Custody personnel 8

This was not the case for all custody personnel however, some of whom were clear that they had both responsibility, and agency, to respond to the different needs of people coming into custody:

'We do have a lot of discretion here and the amount of people that we do see that are vulnerable we have it within our gift to think, well actually I'm not entirely happy with how this person presents to me...' Custody personnel 10 
This was an area where the AAs felt they had an important role to play by being able to spend more time with the detained person, helping them to understand their rights and what was happening to them:

'[the police] they're quite grateful sometimes that we do take the time with them because we find things out that they may have missed or they haven't been told by the young person or by the vulnerable adult'. AA 1

Nevertheless, the role of the AA also raised some concerns regarding roles and responsibilities and, again, an implicit acknowledgement that supporting the communication and information needs of those coming into custody was not necessarily being addressed by the custody personnel who book the person in:

'...if someone comes in with Asperger or autism and on that spectrum they have an AA to be present with them during interview but sometimes they can be in custody for 10, 12, 14 hours before that $A A$ arrives...We get caught in that trap of thinking, well they'll be alright they're going to have an AA... that's not until way down the line, you know? They need to understand now what's going on with them...' Custody personnel 4

Overall, there was recognition from the majority of respondents that understanding the needs of individuals in custody takes time and effective interaction (between professionals in the CJS and also between professionals and the detained person) but that the system does not necessarily allow for this. Although time is often used as a reason for not making changes to practices more generally, frequently masking more deep-seated reservations (e.g. Parsons, Daniels, Porter \& Robertson, 2008), in this case time is genuinely constrained by legal stipulation. Within the reality of such constraints, this analysis points towards opportunities in custody for influencing communication practices in small, but significant ways. For example, the acknowledged automaticity of the booking-in process is an area that could be addressed in training and feedback for custody personnel as a point in the interaction that 
they need to be particularly aware of. In addition, there was an acknowledged need to ensure that efforts are made as early as possible in the interaction between custody personnel and the detained person to support understanding (cf. Bradley, 2009). The role of the AA is an important one in helping an individual to understand what is happening but these interactions tend to take place later in custody, often due to patchy availability of individuals undertaking this role (Jacobson, 2008; Jones \& Talbot, 2010). Consequently, making changes to support communication practices early in the interaction, before the arrival of the AA, is likely to be of benefit to custody personnel and other CJS professionals, as well as the detained person.

\section{Disempowerment through lack of knowledge}

In line with previous research (Jacobson, 2008; Jones \& Talbot, 2010; Cant \& Standen, 2007; Gendle \& Woodhams, 2005), it was clear that there remains a worryingly unknowing set of experiences within the CJS with many respondents across the different professional groups reporting they were unsure about information that may or may not have been provided, or about whether / how someone's needs may be more effectively identified and met. This lack of knowledge or understanding was apparent in accounts provided about the experiences of the detained person and also from the direct experiences of different professionals within the CJS:

'...when you interview a young person you ask them what their order was, they don't know and that's not the fault of in any sense the practitioner involved but it's a case for whatever reason they didn't understand at an earlier stage in the process...' Youth Offending Team personnel 1

'...when somebody comes through from the custody process we have absolutely no idea if there is anything or we have to approach the situation in a different way.' Magistrate court manager 1 
'There is a lack of adequate information when the first contact is made...therefore I go in sometimes blindfolded to what kind of person I'm dealing with, sometimes I don't even know what the vulnerability is.' AA 3

While such accounts do not necessarily add new knowledge to what is already understood about the experiences of responding to vulnerable individuals within the CJS, it is important to confirm existing observations from the perspectives of new respondents; their comments are powerful reminders of the continuing disenfranchised situation in which vulnerable individuals find themselves within the CJS despite wider recognition of these problems (Bradley, 2009; HMIP, 2014).

Crucially, however, these experiences illustrate that it is not just the detained vulnerable person who is disenfranchised but also the CJS professionals who aim to support them, through their own lack of knowledge or information about specific needs. This is important because such lack of knowledge very likely contributes to the lack of agency, implied by many of our respondents discussed above, regarding actions that could be taken to improve the situation. While the need for ongoing awareness raising and training about identifying and responding to vulnerable people in custody remains, such a focus on individual responsibility is likely to have limited impact without more universal, structural changes for supporting the needs of professionals within the CJS (cf. Diesfeld et al., 2008). Certainly, Jacobson (2008) argued that, 'there is a case for providing greater statutory support for suspects with learning disabilities and learning difficulties' (p. viii). In other words, structures and approaches to supporting communication needs should be mandated in order to embed them in practice in order to potentially enable and empower personnel to respond differently than at present.

\section{Panic and fear: a tinderbox environment}

The suggested need for mandated change is sharply illustrated by comments that reveal the frightening and challenging, often threatening and sometimes chaotic, environment of custody and how this can dramatically influence communication and interaction: 
'...you do get genuine people that are really quite scared of being in here and genuinely quite confused and just overwhelmed by the whole process...' Custody personnel 13

'One of the major things is that people are quite stressed and upset and so find it quite hard to process information... that's probably one of the most difficult parts of it.' Legal Representative

The ways of communicating, and lack of understanding that this can reveal or provoke, can also give rise to negative feelings which have a further impact on behaviour:

'...if they don't understand then people get aggrieved they get upset they get stressed.' Custody personnel 4

Thus, according to the reported experiences of CJS professionals there is a negative spiral of interaction that can be initiated by the provision of rights and entitlements in the early stage of custody:

'In the booking in process you always tell them why they've been arrested, why it was necessary to arrest them so all of those things if I'm going to get a problem it's generally at those stages because they don't agree with why they've been arrested ...' Custody personnel 7

One of the Custody Inspectors described this stressful context as 'high risk'. Indeed, the tension inherent within such an environment was also expressed or implied by many CJS professionals as something that could give rise to an eruption or escalation of behaviours very quickly:

'...people in that environment react a lot more, they are a lot more volatile than they would be maybe in a learning environment for example...You're dealing with a different type of person really a lot of the time.' Custody personnel 7 
'...because the medical evidence would suggest that even if someone is presenting well the custody environment is quite stressful and it could trigger an adverse reaction in them...' Custody personnel 1

Consequently, this context suggests that putting procedures in place early in the process that may help to keep the situation calm or defuse an escalation in tension could be important in facilitating communication practices that are helpful for both the detained person and the professionals who support them. The following section provides some further insights into how an ostensibly small change to the rights and entitlements notice could actuate more helpful interactions between professionals in the CJS and vulnerable suspects.

\section{Language and communication, and the potential power of the text as a tool}

There was clear acknowledgement from many of the respondents that much of the responsibility for supporting communication laid with the professionals interacting with the vulnerable detainee, rather than the detainee themselves:

‘...there's a huge amount at stake, they are depending on you, putting their trust onto you...it's up to the professionals to ask the right questions and not just demanding a yes or no answer.' Family Barrister

The Widgit Symbol notice was seen as a very positive development by the majority of respondents, by providing a tool that could initiate new ways of communicating through the use of simplified language and the use of images. These new or different ways of communicating were both implicit and explicit. For example, respondents used adjectives such as 'reassuring', 'friendly', 'accessible', and 'engaging' when describing the Widgit Symbol notice, suggesting that there were implicit messages being conveyed through the deployment of the Widgit notice about taking rights, and communication needs, seriously within the CJS: 
'...what we are not doing is saying here are the rules take it or leave it, you know, actually we need you to understand this...it would probably make them feel a lot more comfortable.' Custody personnel 10

The possibility of the Widgit notice for ameliorating some of the pressures of time was also suggested as helpful:

'For the detainee it gives them a bit more clarity and I think it gives them that time just to look at the pictures and give them a prompt as to this is what it's about so I think, from my own point of view ...what I liked that when I've finished booking in the DP [detained person] I'd like them to feel confident that they know what their rights are and confident that they are going to be treated fairly.' Custody personnel 4

More explicitly, from those who had used the Widgit notices in the pilot project there were reports that the different communication format had made a difference to some people entering custody:

'the funny thing was everyone always went to that one...[pointing to the Widgit symbol sheet]...whether it was just because it was a smaller leaflet or they wanted to know what it was and then they would pay more attention to that...' Custody personnel 6

'it's really made a difference with the normal forms that we've got here, juvenile's I've found just look at them and leave them there whereas the Widgit forms they've picked up and started reading and actually taken them away with them...whereas they don't read the big leaflet so they don't know the smaller rights that ...things like pen and paper and phone calls and that.' Custody personnel 3

The possibility that this more accessible way of presenting information could also have an impact at the earliest stages, preventing escalation of tension and behaviour, was also suggested (though not witnessed or reported in practice): 
'...that's very much a case of give us whatever we can to use that might help us out to look after a DP [detained person] who, you know, might actually on this occasion engage with us far more, be more open and we can prevent...something unpleasant happening.' Custody personnel 1

[there is] a lot of aggression and conflict and anything could arise, I think that [the leaflet] could be really stabilising.' Youth Offending Team personnel 2

There was also acknowledgement that such a tool should not be seen as a shortcut to effective communication, but should be seen as a helpful part of how information is communicated:

'I think something like that would be helpful to the vast majority of people who come into custody... as long as it's clear that they are not an exhaustive answer to everything...' Solicitor 1

\section{Conclusions}

By using the deployment of the written rights and entitlements notice as a device for exploring communication needs and practices within the early stage of custody (cf. Smith, 2001; Walby, 2005), this research illustrates the challenges faced by vulnerable suspects as well as the professionals who support them regarding how to meet communication needs effectively. The challenges included the embedded, ossified nature of existing communication practices, the 'ticking clock' of custody, as well as the volatile environment within which communication takes place. Discussions also revealed the disempowerment and lack of agency felt by many CJS professionals within the liminal context of custody, and the resulting communication breakdowns, with important judicial implications, that can result. While some of these themes reflect and confirm the observations of others in reporting the challenges of meeting the needs of vulnerable detainees (e.g. Cant \& Standen, 2007; Gendle \& Woodhams, 2005), there were also positive indicators demonstrating scope, and support, for changes with regard to how more effective communication could be 
initiated via the introduction of a rights and entitlements notice in more accessible form. This is not to say that such an accessible form should necessarily be symbol-based; there is much more research needed that compares different formats and considers the pros and cons of each with both personnel and the detained person before such a conclusion could be drawn.

Encouragingly, there was no sense in any of the discussions that the detained person was undeserving or unworthy of careful treatment, responsive to their individual needs; the overwhelming reaction to the idea of the Widgit Symbol notice was welcoming and positive. This is unlike, for example, reports on prison officers who tend to position prisoners as 'ghosts in the machine' (Scott, 2008; p. 178), without the same rights and moral consideration as those outside prison. Perhaps because of the liminal, and therefore ambiguous, status of detained persons in custody (before charge and possible conviction), it could be that custody personnel are less likely to have 'neutralised' (Scott, 2008; p. 173) their normal moral commitments to those for whom they are responsible. There was also little evidence that vulnerable detainees were blamed for their own lack of understanding; indeed, there was a strong social model approach to disability evidenced through the accounts of many of the respondents, recognising that the structures, processes and practices of the CJS are exclusionary and unhelpful and that there is responsibility on professionals within the CJS to try to make changes (cf. Diesfeld et al., 2008). Nevertheless, there was a wider sense in which vulnerable detainees were somewhat ghost-like due to the lack of knowledge and awareness about learning disabilities and difficulties, and disability more generally, reported by many of the CJS professionals.

There was no lack of concern about this situation but a lack of apparent agency with regard to implementing changes to address the concerns. The main challenge was that individuals felt disempowered from being able to help or to change practices, processes or procedures within the complex and frequently stressful environment of custody. Consequently, by equipping CJS professionals with appropriate and useful tools that can be used to explicitly 
demonstrate a commitment to meeting the communication needs of people in custody, as well as potentially initiating communication practices that enable the detained person to engage more meaningfully with the information provided, there is a chance to influence practices positively. Such changes would need to be mandated, and embedded in the structures and processes of custody, in order to begin to have any influence, not least because of the challenges of identifying vulnerable suspects in the first place. In our pilot project (Parsons \& Sherwood, 2015) the use of the Widgit Symbol notice was discretionary, resulting in only a small proportion of potentially vulnerable detained persons receiving them.

As Jacobson (2008) argues, an increase in statutory support for vulnerable suspects, through the provision of appropriate and accessible resources for CJS professionals, '...could serve to enhance justice by protecting the welfare and rights of these [vulnerable] individuals...but also by making prosecution a viable option in cases which might otherwise be inappropriately discontinued or diverted' (p.36). Consequently, there are benefits for the detained person but also for the CJS more widely, something that was also recognised by our respondents. As a cautionary note, mandated practices can, of course, become standardised and reified over time through familiarity (e.g. Arnold, 2008), thereby eventually limiting the potential longevity of the impact of changes. However, as one of our respondents said:

'I don't think it would do any harm and if it helps one out of 10 people to understand the process that you wouldn't normally have given one of those to, then you've done the right thing haven't you?' Custody personnel

Thus, as one of the steps that could be taken to make 'reasonable accommodations' for people with learning disabilities and difficulties within the CJS (UNCRPD, 2006), the mandated introduction of a rights and entitlements notice in a more accessible form could be a valuable step in the right direction. Moreover, given the well-established challenges of identifying offenders with disabilities or difficulties by frontline officers (e.g. Jacobson, 2008), the reluctance of individuals to admit to difficulties (Talbot \& Jones, 2010), and the 
possibility that many individuals do not identify or label themselves as having learning disabilities or difficulties until they get to custody (Williams et al.,2015), adopting a universal approach of giving accessible information to everyone entering custody would potentially begin to meet more communication needs at the earliest opportunity (cf. Bradley, 2009).

Of course, there are limitations to our findings and, therefore, conclusions. We were not able to observe communication practices directly, or gain the perspectives of detained persons about their experiences generally, or the Widgit Symbol notice in particular. Instead, we were reliant on self-reports and perceptions of the CJS professionals who interacted directly with those in custody. Observing communication would be essential for providing a more holistic understanding about the ways in which a mandated text could influence the interactions that take place early on and, therefore, examine whether there is a ripple effect that extends to subsequent interactions within custody. In addition, conversation analysis of recordings of police interviews can be very insightful for revealing unconscious bias towards vulnerable witnesses or complainants (Antaki, Richardson, Stokoe, \& Willott, 2015) and so this would be a useful direction for future research with vulnerable detainees too. Nevertheless, as 'representatives of the state' (Bennett, Crewe \& Wahidin, 2008; p.2), the perspectives of custody personnel in particular offer important insights into power, resources and practices within the CJS that form a vital part of the overall picture. Finally, the involvement of current or ex-prisoners with learning difficulties or disabilities who have experienced detention would also be vital in augmenting our understanding about how communication can be managed in more effective ways. It is essential to retain a focus on the bi-directional and mutually influential nature of communication in order to better understand the impact and implications of the challenges from the perspectives of detained persons and also professionals within the CJS. 


\section{References}

Antaki, C., E. Richardson, E. Stokoe and S. Willott, 2015. Police interviews with vulnerable people alleging sexual assault: probing inconsistency and questioning conduct. Journal of Sociolinguistics, 19(3): 328-350.

Arnold, H. 2008. The experience of prison officer training. In J. Bennett, B. Crewe, and A. Wahidin (Eds.) Understanding Prison Staff (pp. 399-418). Abingdon, Oxon, UK: Routledge.

Axinn, W.G. and L. D. Pearce. 2006. Mixed Method Data Collection Strategies. New Perspectives on Anthropological and Social Demography. Cambridge, UK: Cambridge University Press.

Bailey, A., O. Barr, and B. Bunting. 2001. Police Attitudes toward People with Intellectual Disability: An Evaluation of Awareness Training. Journal of Learning Disabilities, 4(4): 344-350.

Bennett, J., B. Crewe, and A. Wahidin (Eds.) Understanding Prison Staff. Abingdon, Oxon, UK: Routledge.

Bradley, K. 2009. The Bradley Report: Lord Bradley's review of people with mental health problems or learning disabilities in the criminal justice system. Retrieved from http://www.centreformentalhealth.org.uk/pdfs/Bradley report 2009.pdf [last accessed 1st July 2015].

Cant, R. and P. Standen. 2007. What professionals think about offenders with learning disabilities in the criminal justice system. British Journal of Learning Disabilities, 35(3): 174-180.

College of Policing 2015. Mental ill health and learning disabilities. Retrieved from https://www.app.college.police.uk/app-content/detention-and-custody-2/detainee-

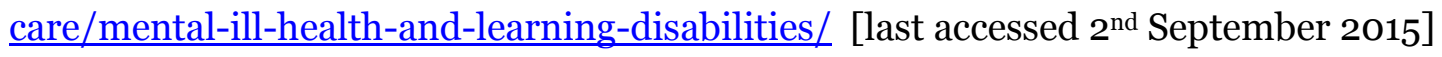


Denscombe, M. 2010. The good research guide: for small scale social research projects. Maidenhead, UK: McGraw Hill/Open University.

Diesfeld, K., M. McLean, T. Phelan, P. Patston, W. Miller-Burgering and R. Vickery. 2008. The challenge of designing optimum legal services for disabled people: the New Zealand experience. Disability \& Society, 23(5): 431-443.

Dowse, L. 2009. Some people are never going to be able to do that. Challenges for people with intellectual disability in the $21^{\text {st }}$ century. Disability \& Society 24(5): 571-584

Gendle, K. and J. Woodhams. 2005. Suspects who have a learning disability: Police perceptions toward the client group and their knowledge about learning disabilities. Journal of Intellectual Disabilities, 9(1): 70-81.

Goodley, D. 2011. Intersections: Diverse Disability Studies. Chapter 3. In Disability Studies: An Interdisciplinary Introduction, 33-47. London: Sage.

Gudjonsson, G. H., I. C. Clare and P. Cross. 1992. The revised PACE "Notice to Detained Persons": how easy is it to understand? Journal of the Forensic Science Society, 32(4): 289299.

Harvey, J. 2005. Crossing the boundary: the transition of young adults into prison. In A. Liebling \& S. Maruna (Eds.). 2005. The Effects of Imprisonment (pp. 232-254). Cullompton, Devon, UK: Willan Publishing.

Hellenbach, M. 2012. Learning disabilities and criminal justice: custody sergeants' perceptions of alleged offenders with learning disabilities. British Journal of Learning Disabilities, 40(1): 15-22.

Henshaw, M., and S. Thomas. 2012. Police encounters with people with intellectual disability: prevalence, characteristics and challenges. Journal of Intellectual Disability Research, 56(6): 620-631. 
Her Majesty's Inspectorate of Probation (HMIP). 2014. A joint inspection of the treatment of offenders with learning disabilities within the criminal justice system - phase 1 from arrest to sentence. Retrieved from www.justive.gov.uk [last accessed $23^{\text {rd }}$ January, 2015].

Home Office (2014) Notice of rights and entitlements: a person's rights in police detention. Retrieved from https://www.gov.uk/notice-of-rights-and-entitlements-a-persons-rights-inpolice-detention [last accessed 1st July 2015].

Jacobson, J. 2008. No one knows: police responses to suspects learning disabilities and learning difficulties: a review of policy and practice. Prison Reform Trust (PRT). Retrieved from http://www.prisonreformtrust.org.uk/Publications/vw/1/ItemID/88 [last accessed $1^{\text {st }}$ July 2015].

Jewkes, Y. 2005. Loss, liminality and the life sentence: managing identity through a disrupted life course. In A. Liebling and S. Maruna (Eds.). 2005. The Effects of Imprisonment (pp. 366-388). Cullompton, Devon, UK: Willan Publishing.

Jones, G. and J. Talbot. 2010. Editorial - No One Knows: The bewildering passage of offenders with learning disability and learning difficulty through the criminal justice system. Criminal Behaviour and Mental Health, 20(1): 1-7.

Keilty, J. and G. Connelly. 2001. Making a Statement: An exploratory study of barriers facing women with an intellectual disability when making a statement about sexual assault to police. Disability \& Society, 16(2): 273-291.

Murphy, G. and I. C. Clare. 1998. People with learning disabilities as offenders or alleged offenders in the UK criminal justice system. Journal of the Royal Society of Medicine, 91(4): 178-182.

Nind, M. and J. Seale. 2009. Concepts of access for people with learning difficulties: towards a shared understanding. Disability \& Society, 24(3): 273-287. 
Parsons, S., H. Daniels, J. Porter, and C. Robertson. 2008. Resources, staff beliefs and organisational culture: first- and second-order factors in the use and implementation of ICT for adults with intellectual disabilities. Journal of Applied Research in Intellectual Disabilities, 21(1): 19-33.

Parsons, S. and G. Sherwood. 2015. The Widgit Symbol Custody Sheet Pilot Project. Southampton Education School: University of Southampton, UK. Retrieved from www.widgit.com/custodysheets [last accessed $13^{\text {th }}$ August 2015].

Parsons, S. and G. Sherwood. in press. A pilot evaluation of using symbol-based information in police custody. British Journal of Learning Disabilities. doi: 10.1111/bld.12140

Poynter, J. 2011. People with learning disabilities who come in contact with the Criminal Justice System, Tizard Learning Disability Review, 16(2): 49 - 53.

Prison Reform Trust. 2013. Prison: the facts - Bromley Briefings Summer 2013. Retrieved from http://www.prisonreformtrust.org.uk/Portals/o/Documents/Prisonthefacts.pdf [last accessed 13th August 2015].

Rock, F. 2006. Looking the other way: Linguistic ethnography and forensic linguistics. In $U K$ Linguistic Ethnography Forum Papers. Retrieved from http://www.researchgate.net/profile/Frances Rock/publication/255644113 Looking the other way Linguistic ethnography and forensic linguistics/links/54118d910cf264cee28 b3f53.pdf [last accessed 1st July 2015].

Scott, D. 2008. Creating ghosts in the penal machine: prison officer occupational morality and the techniques of denial. In J. Bennett, B. Crewe, and A. Wahidin (Eds.) Understanding Prison Staff (pp. 168 - 186). Abingdon, Oxon, UK: Routledge.

Smith, D. E. 2001. Texts and the ontology of organizations and institutions. Studies in Cultures, Organizations and Societies, 7(2): 159-198. 
Suttner, R. 2010. Rethinking and re-remembering prison: reification, agency and liminality. Psychology in Society, 39: 3-20.

Swift, P., K. Johnson, V. Mason, N. Shiyyab and S. Porter. 2013. What happens when people with learning disabilities need advice about the law? Norah Fry Research Centre: University of Bristol, UK. Retrieved from

http://www.legalservicesconsumerpanel.org.uk/ourwork/vulnerableconsumers/Legal\%20A dvice\%20Learning\%20Disabilities\%20Final\%20Report.pdf [last accessed 1st July 2015].

Talbot, J. 2010. Prisoners' voices: experiences of the criminal justice system by prisoners with learning disabilities, Tizard Learning Disability Review, 15(3): 33-41.

Ugelvik, T. 2013. Constructing the System in a Remand Prison. In J. Gubrium and M. Järvinen (Eds.), Turning Troubles into Problems: Clientization in Human Services (pp. 155169). Abingdon, Oxon, UK: Routledge.

United Nations Convention on the Rights of Persons with Disabilities (UNCRPD). 2006. Retrieved from http://www.un.org/disabilities/convention/conventionfull.shtml [last accessed 1st July 2015].

Walby, K. 2005. How closed-circuit television surveillance organizes the social: An institutional ethnography. The Canadian Journal of Sociology, 3o(2): 189-214.

Williams, V., P. Swift and V. Mason, 2015. The blurred edges of intellectual disability. Disability \& Society, 30(5): 704-716.

Young, D.A. and R. Quibell. 2007. Why Rights are Never Enough: Rights, intellectual disability and understanding. Disability \& Society 15 (5): 747-764.

Young, M. 1986. An anthropology of the police: semantic constructs of social order. Unpublished Doctoral thesis, Durham University. Available from http://etheses.dur.ac.uk/6790/ 


\section{Tables}

Table 1: representation of direct quotes used in the paper

\begin{tabular}{|l|l|}
\hline $\begin{array}{l}\text { Participant reference used in } \\
\text { the text }\end{array}$ & $\begin{array}{l}\text { Number of direct quotes used } \\
\text { in the paper }\end{array}$ \\
\hline Custody personnel 1 & $* *$ \\
\hline Custody personnel 2 & $*$ \\
\hline Custody personnel 3 & $*$ \\
\hline Custody personnel 4 & $* * *$ \\
\hline Custody personnel 5 & \\
\hline Custody personnel 6 & $*$ \\
\hline Custody personnel 7 & $* * *$ \\
\hline Custody personnel 8 & $* * *$ \\
\hline Custody personnel 9 & \\
\hline Custody personnel 10 & $* *$ \\
\hline Custody personnel 11 & $* *$ \\
\hline Custody personnel 12 & $*$ \\
\hline Custody personnel 13 & $* *$ \\
\hline Custody personnel 14 & \\
\hline Barrister & $* *$ \\
\hline Solicitor 1 & $*$ \\
\hline Solicitor 2 & $*$ \\
\hline Youth offending team 1 & $*$ \\
\hline Youth offending team 2 & $*$ \\
\hline Appropriate Adult 1 & $*$ \\
\hline Appropriate Adult 2 & $*$ \\
\hline Appropriate Adult 3 & $*$ \\
\hline Appropriate Adult 4 & \\
\hline Appropriate Adult 5 & \\
\hline Appropriate Adult 6 & \\
\hline Appropriate Adult 7 & $* *$ \\
\hline Legal representative & $*$ \\
\hline Magistrate court 1 & \\
\hline Magistrate court 2 & \\
\hline
\end{tabular}




\section{Figures}

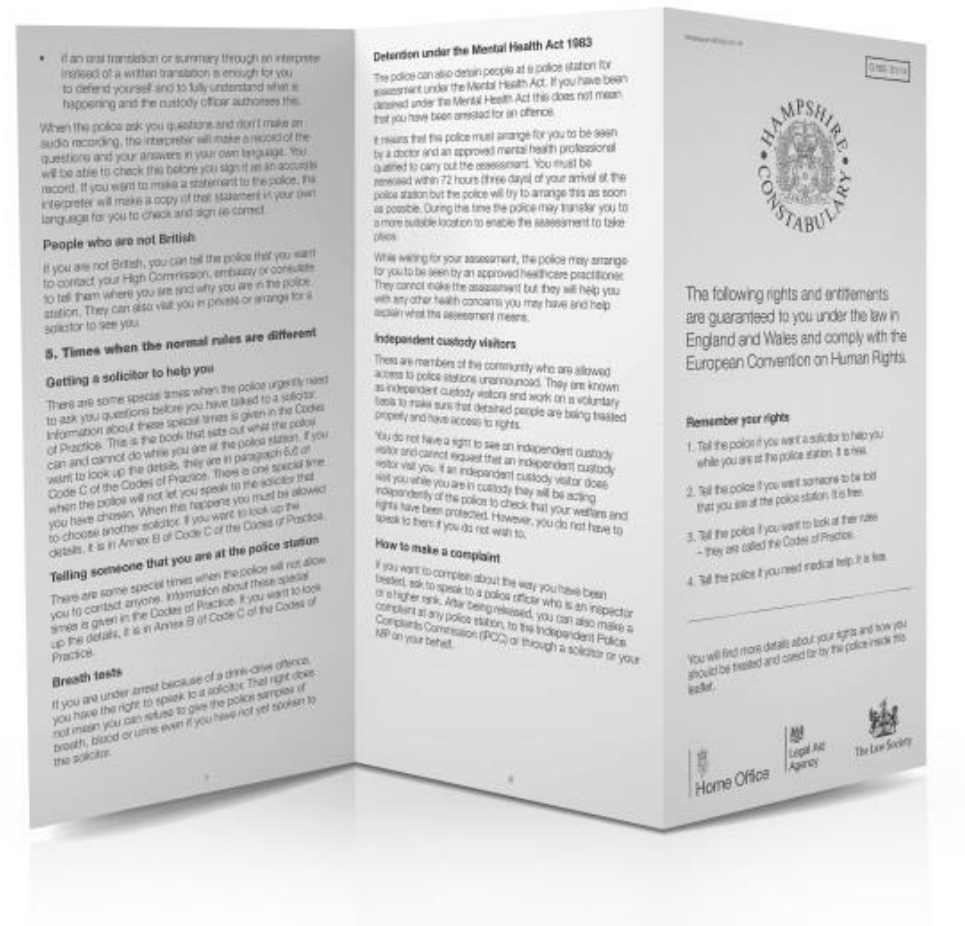

Fig 1: Standard rights and entitlements notice 


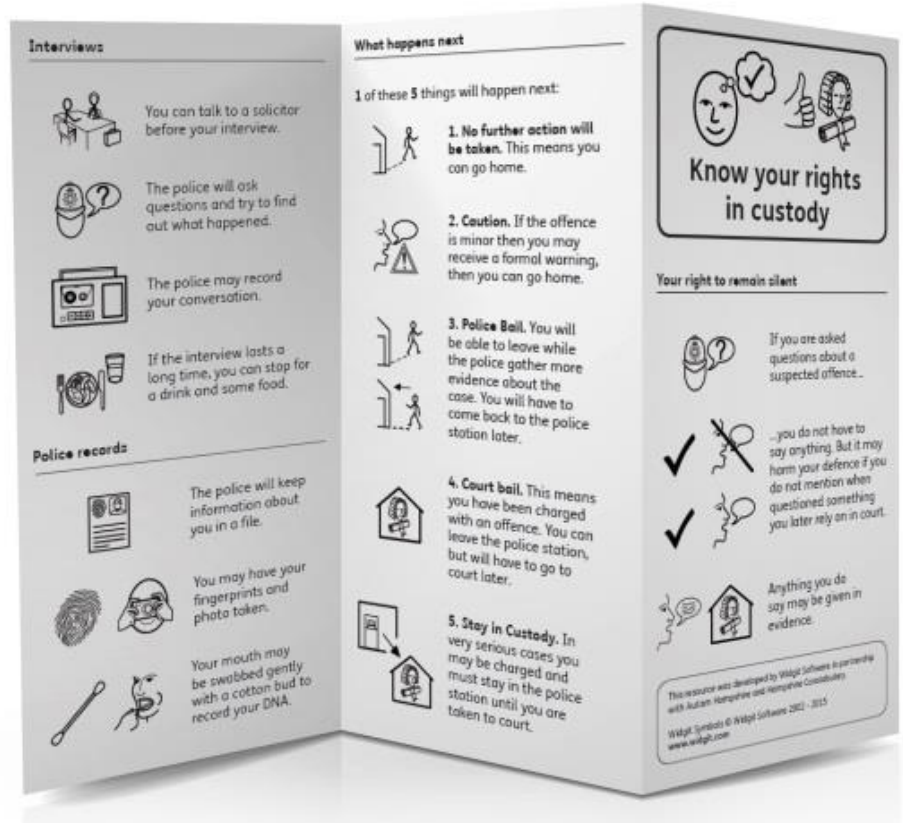

Fig 2: Widgit Symbol rights and entitlements notice [reproduced with permission from Widgit Software] 


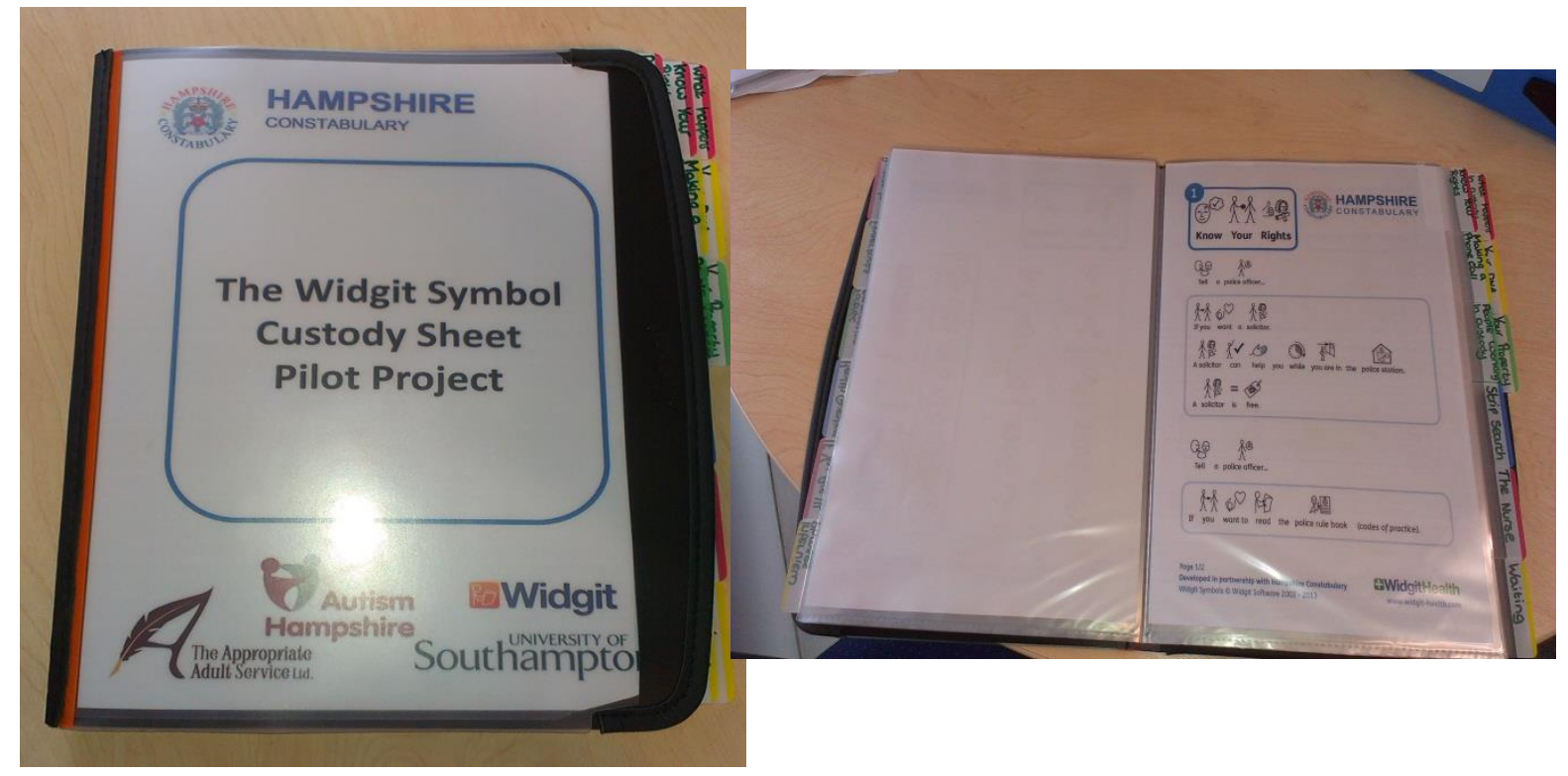

Figure 3: Folders containing laminated sheets with additional information. For a full list of the individual sheets see Parsons \& Sherwood (2015) 


\section{Notes}

'The term 'vulnerable' throughout the paper refers to adults with learning disabilities and difficulties, as well as young people (who may also have learning difficulties or disabilities).

ii The most recent guidance on the safe detention of people in custody from the College of Policing (2015) includes specific sections on mental health, and learning difficulties or disabilities and definitions of these terms. This guidance makes it clear that: 'Those with learning disabilities/difficulties should have an appropriate adult when being dealt with in a custody environment. Furthermore officers and staff should consider using registered intermediaries and other forms of communication where appropriate' (Detention and custody, section 2.3 Learning disabilities or difficulties, para. 4).

iii This term is treated as a proper noun in this paper because the Appropriate Adults involved were all members / employees of organisations who provide this service within the CJS. The use of the proper noun here distinguishes between these professional Appropriate Adults and those appropriate adults who may be designated by the detained person [who could be a family member, friend, or someone else known to the person]. 